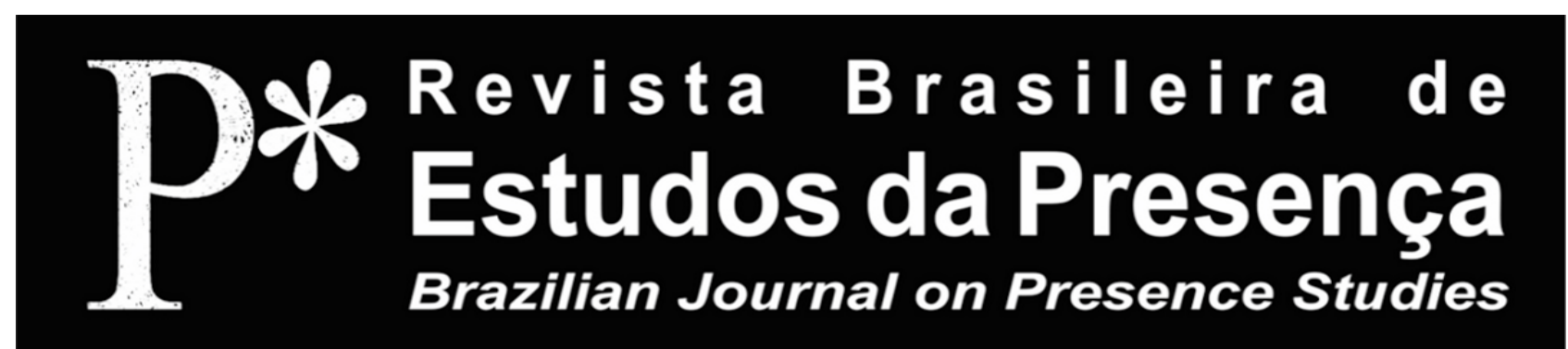

PROCESSOS DE CRIAÇÃO

E-ISSN 2237-2660

\title{
Do Movimento ao Som, Do Som ao Movimento: relações bioculturais entre dança e música
}

\author{
Andréia Nhur' \\ 'Universidade de São Paulo - USP, São Paulo/SP, Brasil
}

RESUMO - Do Movimento ao Som, Do Som ao Movimento: relaçóes bioculturais entre dança e música - $\mathrm{O}$ presente artigo versa sobre as interaçóes entre corpo e som em processos de criação demarcados pela relação entre dança, música e experimentos sonoros. A partir das obras Peças Fáceis, do Grupo Pró-Posição, e $Z$, de Alejandro Ahmed, o estudo aventa aproximaçóes teóricas entre os campos da Dança e da Cognição Musical Incorporada, a fim de refletir sobre processos de percepção e mediação em corpos-artistas que se movem, interagem com instrumentos musicais e vocalizam. As obras analisadas, cada uma à sua maneira, ventilam som e movimento como processos inacabados, cuja culminância se dá pelo atravessamento mútuo e biocultural entre corpo e ambiente.

Palavras-chave: Dança Contemporânea. Processos de Criaçáo. Movimento. Som. Ciências Cognitivas.

ABSTRACT - From Movement to Sound, from Sound to Movement: biocultural relations between dance and music - This article discusses the interactions between body and sound in the creative process characterized by the relation between dance, music and sonic experiments. Based on the production Peças Fáceis, by Pró-Posição Group, and $Z$, by Alejandro Ahmed, this study presents theoretical approaches between Dance Studies and Embodied Music Cognition fields. It also intends to discuss what happens to the bodily perception and mediation process in artists who dance, play musical instruments and produce vocal sounds. The analyzed plays, each one in its way, defend the idea that sound and movement are no-concluded processes crossed constantly by mutual and biocultural interactions with the environment.

Keywords: Contemporary Dance. Creative Processes. Movement. Sound. Cognitive Sciences.

RÉSUMÉ - Du Mouvement au Son, du Son au Mouvement: relations bioculturelles entre la danse et la musique - Cet article porte sur les interactions entre le corps et le son, dans les processus de création délimités par la relation entre danse, musique et expérimentations sonores. À partir des œuvres Peças Fáceis du Groupe Pró-Posição, et $Z$ d'Alejandro Ahmed, cette étude présente des rapprochements théoriques entre la Danse et la Cognition Musicale Incarnée, afin de réfléchir sur les processus de perception et de médiation des corps des artistes qui bougent, jouent des instruments de musique et vocalisent. Les œuvres analysées, chacune à sa façon, montrent que le son et le mouvement sont des processus inachevés, dont leur apogée est le croisement mutuel et bioculturel entre le corps et l'environnement.

Mots-clés: Danse Contemporaine. Processus de Création. Mouvement. Son. Sciences Cognitives. 


\section{O Corpo no Centro da Cena Híbrida}

Os panoramas da dança e do teatro ocidental enunciaram, ao longo de suas histórias, inúmeros exemplos de integraçáo entre diferentes artes. A dança pós-moderna norte-americana, que eclodiu na década de 1960, o thanztheater alemão dos anos 70 e o teatro físico emergente nos anos 80 do século XX, por exemplo, lançaram obras híbridas, em que lógicas compositivas distintas se misturavam, evidenciando não só cenas justapostas, mas também corpos capazes de transitar entre vários fazeres. No século XXI, cada vez mais experiências cênicas têm utilizado recursos da música, do teatro, da dança e da performance, deflagrando - para além da justaposição de efeitos estéticos ocorrendo paralela ou alternadamente - a necessidade de se pensar a mistura de technés em corpos que transitam por diversos domínios $\operatorname{artísticos}^{1}$.

Os campos teóricos do teatro e da dança, em suas incursóes historiográficas e críticas, têm desenhado leituras advindas dos estudos da recepçáo, da semiótica teatral, da filosofia, dos estudos culturais, da performance e da antropologia, entre outras searas, com vistas a entender a diversidade do fenômeno cênico contemporâneo. $O$ crítico e professor de teatro alemão Hans-Thies Lehmann e seu estudo sobre o teatro pós-dramático, ou os escritos da crítica e historiadora da dança francesa Laurence Louppe, acerca das poéticas da dança contemporânea, são algumas das referências importantes que englobam a discussão estética sobre mistura de linguagens artísticas na contemporaneidade (Lehmann, 2007; Louppe, 2000). Entretanto, ainda são escassas as investigaçóes interessadas nas dimensóes bioculturais, corporais e cognitivas, em diálogo com domínios científicos capazes de averiguar as implicaçôes que habitam os problemas dos corpos em ação nessas experiências híbridas.

O presente estudo se debruça sobre dois trabalhos artísticos com o intuito de refletir sobre as relações entre movimento e som do ponto de vista dos processos medrados pelos corpos, com base em disparadores específicos de criação. Assim, não se trata de observar e discutir os aspectos estéticos de obras em situação de hibridismo de linguagem, mas sim vasculhar em que medida o uso da relação corpo-som afeta a criação artística e de que forma. Para tanto, olharemos para duas peças coreográficas, uma do grupo paulista 
Pró-Posição e outra do grupo catarinense Cena 11, nas quais som e movimento assumem certo protagonismo, para entáo averiguar disparadores e princípios envolvidos em suas criaçóes.

Os trabalhos analisados, além de apresentarem distintas maneiras de abordar a relação entre som e movimento na criação em dança, lançam pistas para a compreensão de como essas instâncias se comunicam no corpo do artista da cena, com base não somente em suas dimensóes poéticas e artísticas, mas também bioculturais e cognitivas.

No livro Biocultural Creators: Toward a New Theory of the Human, a cientista política Samantha Frost (2016) aposta numa mediação entre os campos biológico e cultural por meio de uma inseparabilidade que ressignificaria esses domínios: "A ideia de que os seres humanos são criaturas bioculturais fornece uma base para o desenvolvimento de relatos mais ricos e detalhados de como os mundos material e social são constitutivos da maneira como vivemos e vivenciamos nossas vidas" (Frost, 2016, p. 174).

Desafiando teorias da subjetividade que insistem em apartar natureza e cultura, Frost aposta que os seres humanos são criaturas bioculturais, resultantes da imbricação do biológico e do cultural no corpo. Nesse sentido, a autora defende um espaço de concílio entre as ciências biológicas e as ciências humanas, abrindo campo para estudos interessados tanto nas dimensóes neurocognitivas quanto socioculturais e políticas de fenômenos que envolvem o humano (Frost, 2016).

É sob este prisma que o estudo a seguir buscará olhar para os processos artísticos em questáo: por meio de uma abordagem biocultural dos corpos implicados. Para tanto, o recorte epistemológico das Ciências Cognitivas surge como baliza teórica para realocar o debate artístico para além do campo estético e simbólico.

\section{Peças Fáceis (2017)}

Em Peças Fáceis, obra coreográfica do Grupo Pró-Posição, peças musicais barrocas misturadas a outras referências sonoras servem de material norteador para a criação de coreografias dançadas, cantadas e tocadas, em regime de concomitância ou alternância entre tais tarefas:

Um violáo-corpo, um acordeom-corpo, um corpo-pandeiro, um corpocastanhola. As bailarinas foram despertas para outros fazimentos, que preci- 


\section{Revista

sam apagar os contornos da música e da dança para que ambas se materializem uma na outra. Corpo e sonoridades vão se testando, ensaiando o que pode virar corpo, o que pode virar música (Katz, 2017, p. 36).

O trabalho resultou de um estudo iniciado em 2015, voltado para as formas de afetação mútua entre materialidades do som e do movimento. Em 2016, o projeto se tornou uma plataforma colaborativa em que participaram diversos artistas provocadores, como a compositora e multiinstrumentista Andréa Drigo, a coreógrafa Helena Bastos, o dramaturgo e iluminador Roberto Gill Camargo, a produtora Paola Bertolini e os músicos Ramon Vieira e Márcia Mah, com apoio do Edital Proac no 4/2016 (Programa de Ação Cultural da Secretaria de Cultura do Estado de Sáo Paulo) ${ }^{2}$.

Nessa peça (Figura 1), as artistas Janice Vieira e Andréia Nhur, que são mãe e filha, dividem a cena, compartilhando memórias musicais comuns, a partir de minuetos do Pequeno Livro de Ana Magdalena Bach. Alternando respiraçôes, ruídos, vocalises ${ }^{3}$, vozes em contraponto ${ }^{4}$, percussóes e músicas tocadas em violáo, acordeom e castanholas, os corpos transitam entre gestos e sonoridades, dando a ver uma dança que produz música.

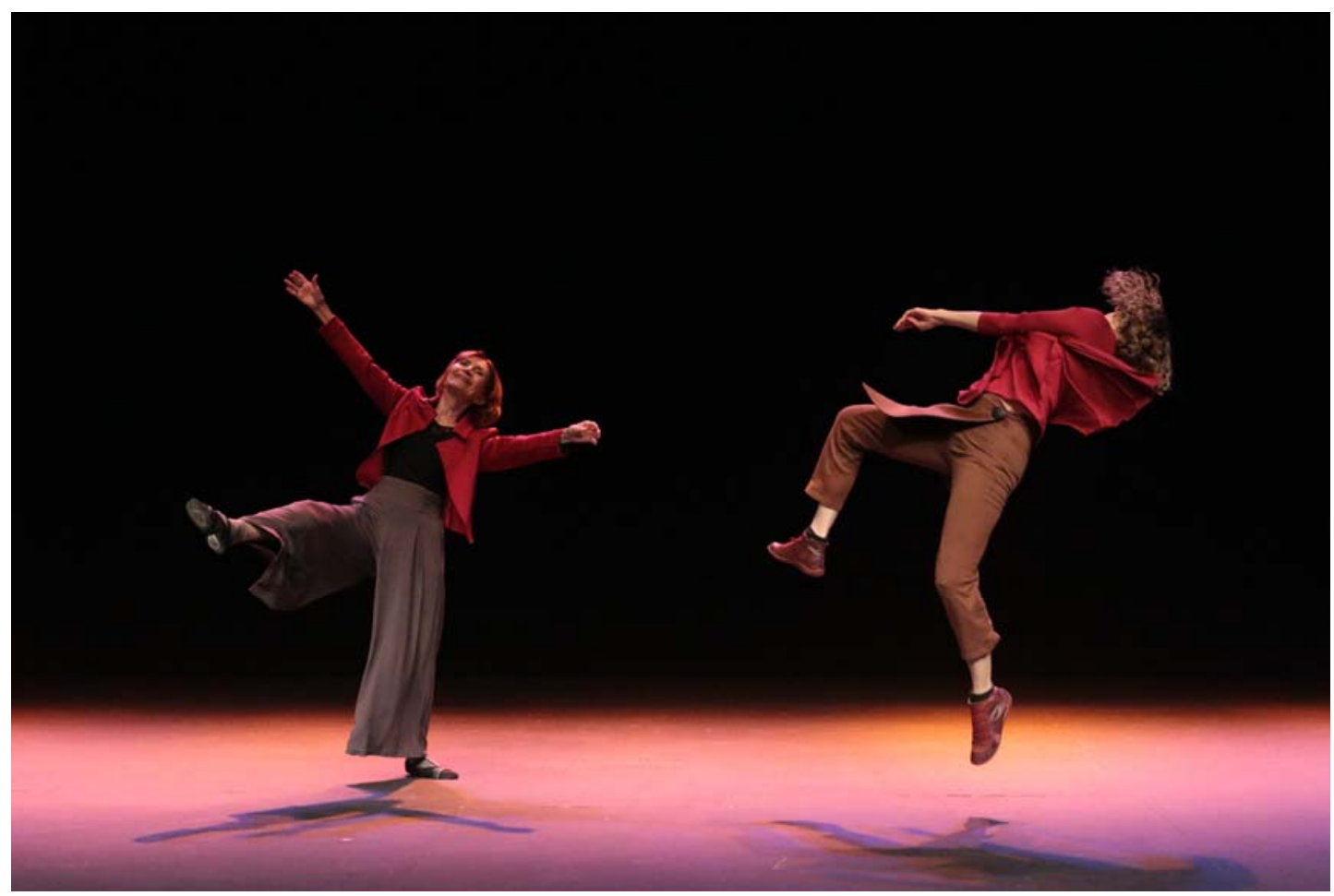

Figura 1 - Peças Fáceis. Fonte: Foto de Paola Bertolini (2019).

O Pró-Posição Dança, grupo fundado em Sorocaba/SP na década de 1970, traz em sua trajetória inúmeros trabalhos edificados sob a junção de 
diferentes artes 5 . Suas produçóes mais recentes, após a retomada do grupo em 2007, são marcadas pela presença de voz cantada e música ao vivo como parte do pensamento coreográfico (Nhur, 2019). Janice Vieira é bailarina, coreógrafa e acordeonista, com vasta formação musical; Andréia Nhur é atriz, bailarina e possui formação em canto, violáo e percussão. Desde 2007, as artistas têm performado juntas nos trabalhos do grupo, sublinhando o trânsito de linguagens artísticas de acordo com seus repertórios pessoais.

Em Peças Fáceis, o interesse particular em explorar corpo e som anuncia um território específico de atuação em que música e dança parecem se tornar zonas de indistinção:

[...] embora estejam apenas as duas no palco, náo se trata de um duo, pois a música se enuncia como uma terceira presença. Não como um personagem, mas como uma fisicalidade. Às vezes, materializa um sopro, um vento ou um balançar, às vezes aparece como um pedido de silêncio na forma de um 'shh' que assobia. Em vez de acumular, pratica um esvaziar constante. Não desenha círculos que se fecham, mas rabiscos que pespontam anúncios que não se completam. [...] Aos poucos, sonoridades vão virando vestígios de melodia, duas vozes vão se desenhando para que dois corpos possam ser identificados pelo movimento que lhes dá forma, movimento esse que tanto vem das sonoridades quanto lhes faz nascer (Katz, 2017, p. 36).

As artistas combinam as açóes de cantar, tocar instrumentos e dançar, gerando uma mobilidade sonora entre cada gesto enunciado (Figura 2). Para nomear esse processo de construçáo de movimento integrado à produçáo organizada de som, o grupo cunhou o termo sonorocoreografia:

Inventamos este termo para nomear uma lógica composicional emergente da combinação entre produção sonora e coreográfica. Embora sirva para categorizar um certo tipo de construçáo artística híbrida - para corpos hábeis em transitar entre a dança e a música - este 'arte-conceito' também pode disparar discussóes complexas acerca das operaçóes cognitivas que habilitam corpos em multitarefas (como dançar cantando, falar dançando ou dançar tocando um instrumento) (Nhur, 2019, p. 195). 

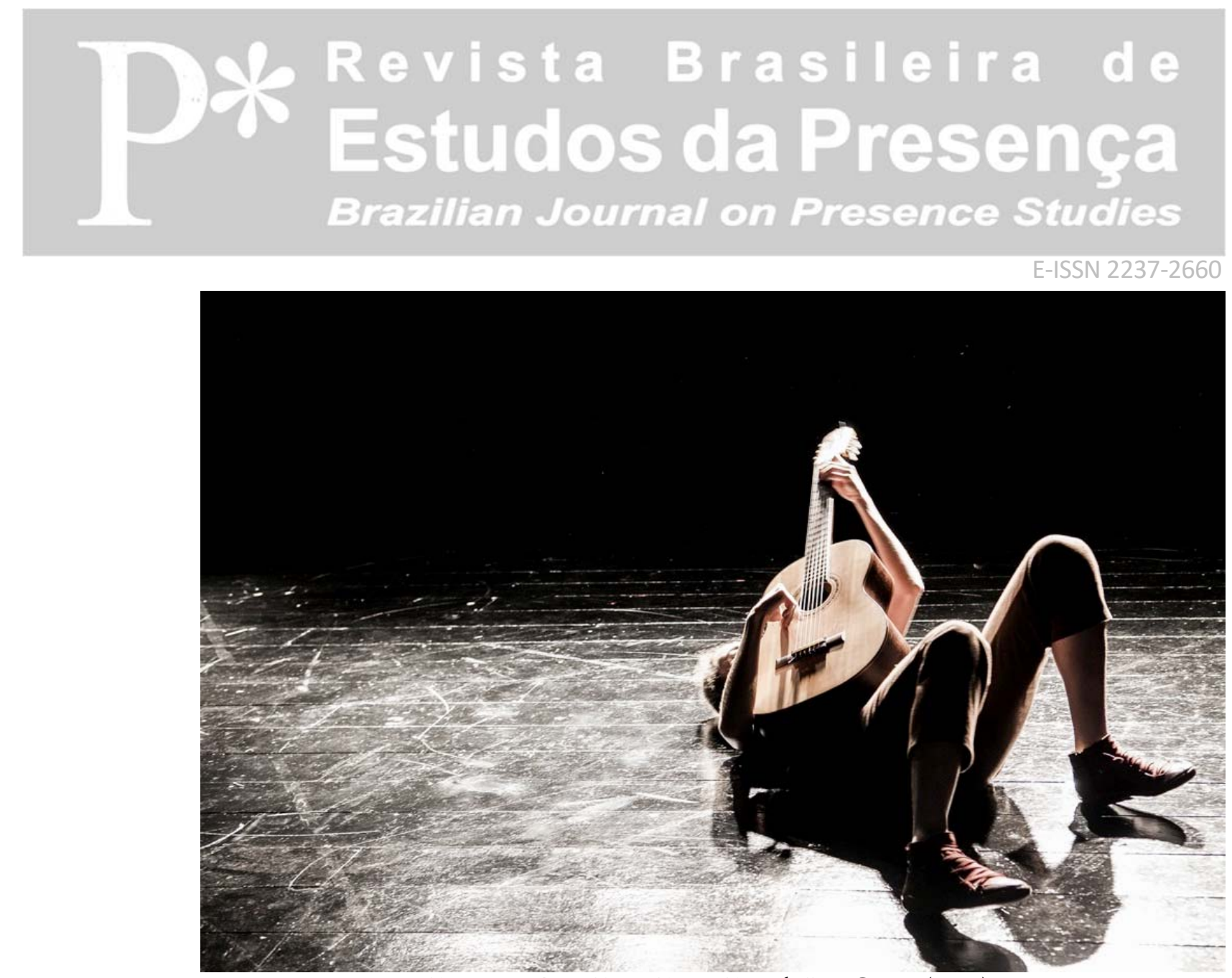

Figura 2 - Peças Fáceis. Fonte: Foto de Inês Corrêa (2017).

A produção sonora, nesse contexto, parece ser edificante de uma linha de atravessamento que ocupa a criaçáo em suas bases compositivas; ao mesmo tempo, o movimento e as formas de organizaçáo do corpo no espaço-tempo denotam que há um traço coreográfico interposto.

Por produção sonora, na obra do Grupo Pró-Posição, podemos entender como um paralelo à compreensão do que é música na concepção de José Miguel Wisnik (2006): tudo o que abarca som, ruído e silêncio num sistema de ordenação.

O jogo entre som e ruído constitui a música. O som do mundo é ruído, o mundo se apresenta para nós a todo momento através de frequências irregulares e caóticas com as quais a música trabalha para extrair-lhes uma ordenação (ordenação que contém também margens de instabilidade, com certos padrōes sonoros interferindo sobre outros) (Wisnik, 2006, p. 33).

Já a palavra coreografia pode ser lida, aqui, sob o prisma de uma série de discussóes que a atualizam continuamente para além das máximas de unidade espaço-temporal e narrativa linear, conforme era creditada em definiçôes oriundas de estudos hegemônicos sobre danças clássicas e modernas ${ }^{6}$. Portanto, náo se trata de usar o termo coreografia como sequenciamento linear de movimentos no espaço, mas sim como organizaçáo espaço- 
temporal e sígnica, ativada por corpos especialistas nas motricidades a que se propóem.

Dentro dessa perspectiva, o Grupo Pró-Posição anuncia a ideia de sonorocoreografia como o recurso que opera movimento, som e voz num jogo coreográfico e sonoro em integração. $\mathrm{O}$ canto mantém seu contorno como voz utilizada entre respiração, balbucio, vibração, vocalise e canção; os instrumentos guardam suas funçóes tonais, mas também ganham outros contornos a partir da exploração de suas materialidades. $\mathrm{O}$ som se alterna entre ruído, silêncio e música, ocupando tonalidades e rítmicas regulares.

A música tonal, grosso modo, explora as possibilidades das alturas, trazendo a melodia e a harmonia para primeiro plano (Wisnik, 2006). No sistema tonal, existe um centro que estabelece um ponto de referência para a hierarquização entre notas. Em $O$ som e o sentido: uma outra história das músicas, José Miguel Wisnik (2006) passa pelo canto gregoriano, pela música tonal moderna e pela música do século XX, apontando as complexidades do jogo entre som, silêncio e ruído em sistemas musicais modais, tonais e seriais. Para além de definiçóes simplificadas, o conceito de tonalidade musical abarca inúmeras discussóes acerca de seu uso na contemporaneidade:

[...] o encurvamento do caminho da música tonal, que se ultrapassa em direção a uma música pós-tonal e antitonal (como será o dodecafonismo e o serialismo), ao mesmo tempo em que evoca de maneira diferida as músicas modais primitivas é o próprio nó e o núcleo das simultaneidades contemporâneas (Wisnik, 2006, p. 45-46).

Falamos da presença de sistemas tonais em Peças Fáceis pois existem oscilaçóes entre melodias, ruídos, timbres e silêncios, fazendo coexistir organizaçóes melódico-harmônicas tonais e antitonais.

E como defendem suas criadoras, movimento e sonoridade são performados por "corpos hábeis" (Nhur, 2019, p. 195) a transitar entre as linguagens da dança e da música. Logo, do ponto de vista do corpo que performa (Figura 3), não estamos falando de uma conexão randômica entre som e movimento, senáo de um desenho constituído por caminhos conjuntos na tarefa de mover e de tocar/cantar. 


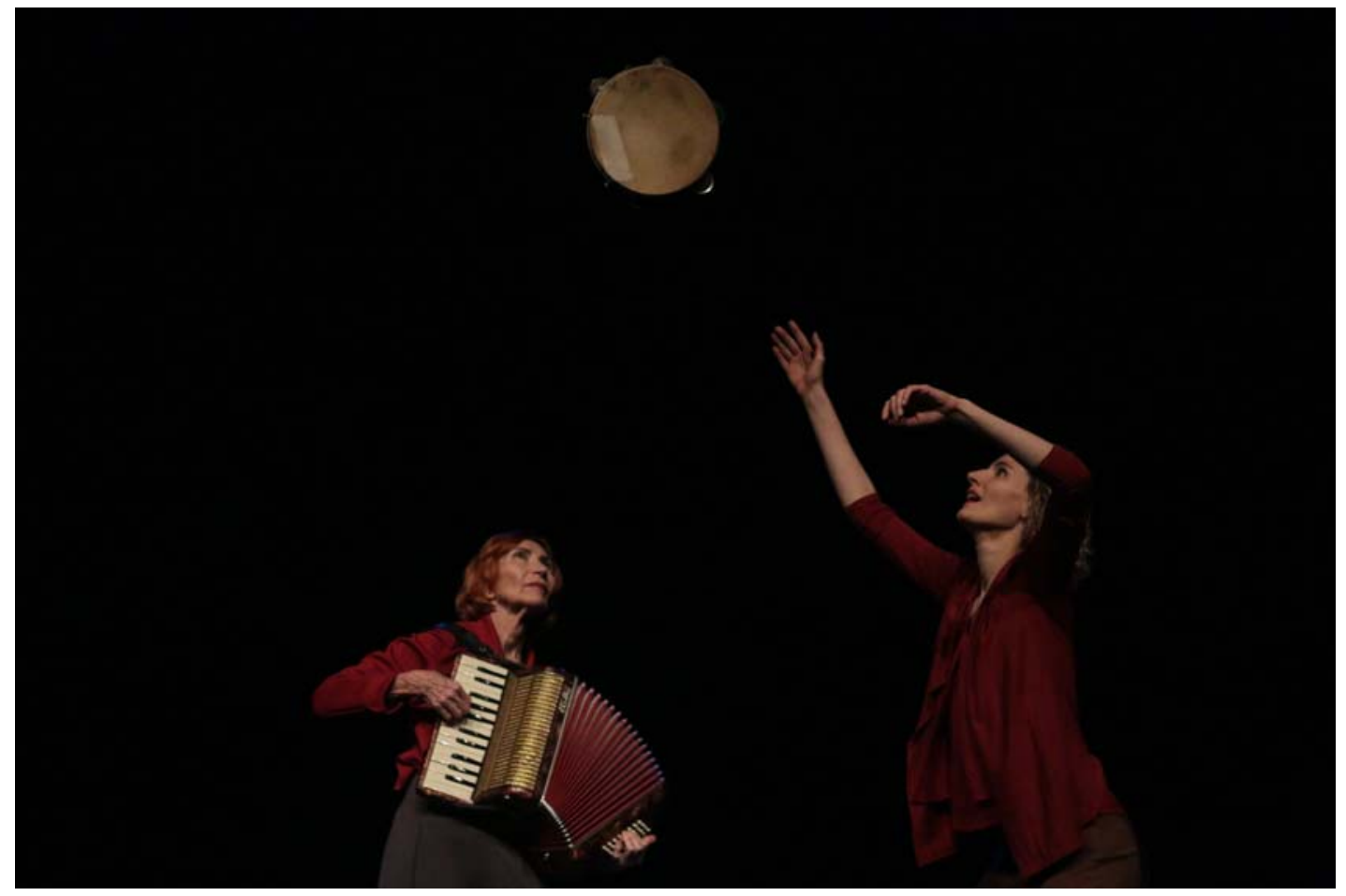

Figura 3 - Peças Fáceis. Fonte: Foto de Paola Bertolini (2019).

\section{$Z(\mathbf{2 0 1 8 )}$}

$Z$ é uma pesquisa e criação em dança com direção e performance do artista Alejandro Ahmed em interação com uma guitarra elétrica e outros materiais como placas magnetizadas e pedais de loopstation (para gravação de sons em sobreposiçáo). Coreógrafo residente, diretor artístico e bailarino do Grupo Cena 11 Companhia de Dança ${ }^{7}$, Ahmed (Figura 4) tem marcado a cena contemporânea desde os anos 1990 com produçóes impactantes, decorrentes de uma pesquisa continuada acerca do corpo, seus limites, suas relaçóes com o ambiente e com o outro.

No solo $Z$, o performer trabalha com sons vocalizados e utiliza a guitarra com intenção de guiar um jogo melódico e cinético a partir de efeitos como reverberação, eco e microfonia. $\mathrm{O}$ trabalho tem direção compartilhada e ensaios de Mariana Romagnani, figurinos e produção de Karin Serafin e iluminação e interlocução sonora de Hedra Rockenbach ${ }^{8}$. 

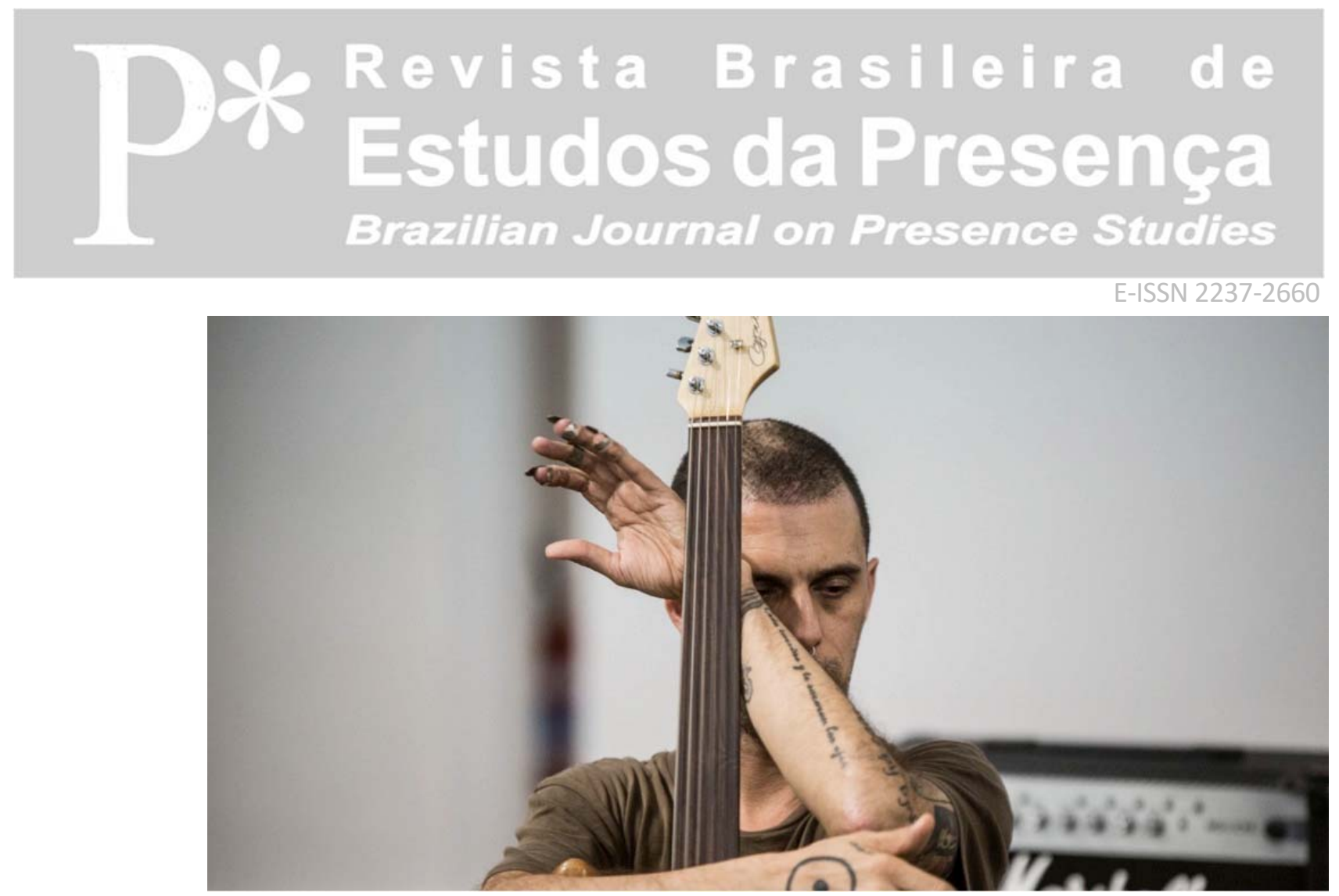

Figura 4 - Alejandro Ahmed em $Z$. Fonte: Foto de Cristiano Prim.

A obra, nomeada como músico-coreográfica, desenvolve-se na imbricação entre as ideias de coreografia e composição generativa. Com vistas a uma criaçáo estruturada na causalidade e na coautoria entre ambiente e corpo, Ahmed traz a composição generativa como tentativa de congregar as noçóes de percepção e adaptação como mecanismos de negociação entre corpos (Serafin, 2018).

Em $Z$, o instrumento é um objeto sonoro destituído de sua função tradicional, ou seja, desprovido de sua lógica tonal. A voz tampouco aparece como sonoridade organizada. Entre ruídos e silêncios, a guitarra é manipulada fora de sua convenção; já a voz aparece como grito, gemido, balbucio, tentativa ou resto de palavra.

[...] Na intersecção entre o corpo-som e o som-matéria poucos são os espetáculos que investigam o vão que determina ao som e corpo habitarem ambos os contextos simultaneamente. É preciso que o performer compreenda sua qualidade física não apenas como gesto, e sim o gesto como ampliaçáo da sonoridade interna do corpo, por conseguinte sua representaçáo. Sendo o som do corpo atuante e contaminável é necessário ainda que o performer encontre os artifícios para reinventar o próprio gesto, afim de que náo seja mera ilustração rítmica. Alejandro Ahmed inclui feito um intermeio ao interno e externo do próprio corpo uma guitarra, para, a partir (mas náo só) de suas qualidades sonoras e vibracionais instituir uma ritualização de como o gesto pode ser anterior ao discursivo, portanto às ilustraçôes [...] (Filho, 2018, blog Antropositivo). 


\section{Revista

Embora esteja sozinho em cena (Figura 5), com a singularidade de suas condiçóes físicas postas em jogo, Ahmed faz emergir, em seu solo, o desdobramento de questóes lançadas ao longo dos mais de 25 anos de pesquisa em dança ao lado do Cena 11.

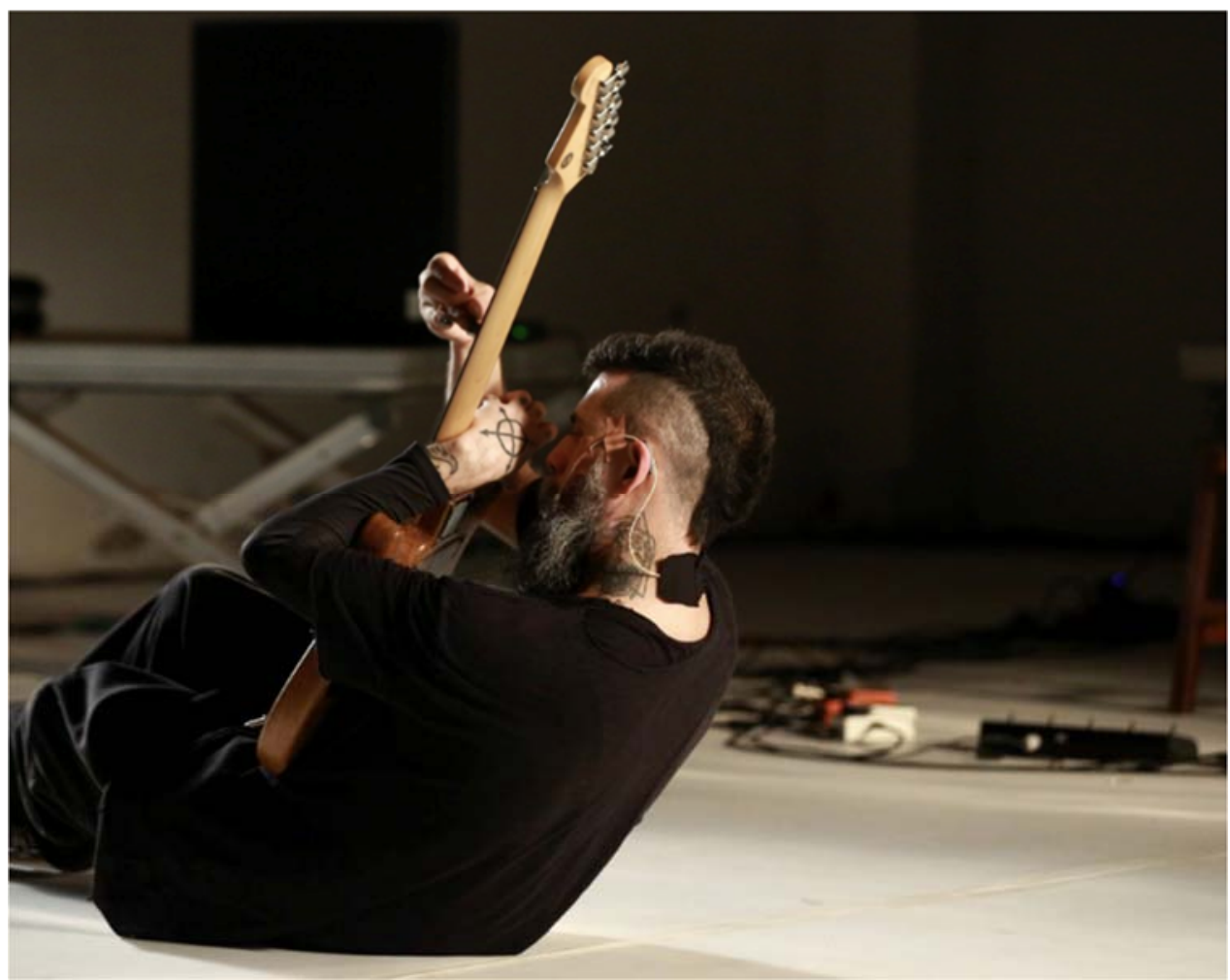

Figura 5 - Alejandro Ahmed em Z. Fonte: foto de Beto Assem.

$\mathrm{Na}$ década de 1990, o grupo se aventurou pela relação entre corpo, cultura pop, punk e tecnologia. Nos anos 2000, alargou as narrativas sobre o risco, com as famosas quedas que demarcaram sua assinatura nesse período. Nos anos 2010, passou a olhar para as questôes fulcrais que movem a ideia de coreografia, trazendo a prontidão como forma de desestabilização dos repertórios do corpo em situações não previstas (Figura 6).

Então, se as noçóes de percepção e adaptação atravessam a feitura de $Z$, asseverando um arranjo intermitente entre corpo e ambiente, essa lógica se faz dos inúmeros traçados que constituíram as trajetórias presentes na história do Cena 11:

Há pelo menos 10 anos, o Grupo Cena 11 passou a produzir trabalhos coreográficos como desenvolvimento de projetos investigativos acerca de questóes de corporalidade, ambiências e seus rebatimentos em comportamento, estabelecendo parâmetros de experimentação em etapas que constituíam-se em formulaçôes chamadas procedimentos. Foi assim que o Projeto skr constituiu-se de 5 


\section{Revista Brasileira

E-ISSN 2237-2660

procedimentos em que foram testados diferentes parâmetros investigativos acerca da ideia de liberdade baseada em disciplina e regras, que resultaram, após 3 anos, no espetáculo Skinerbox. Em 2008, o foco nas relaçóes entre corporalidade e ambiência mediada por recursos tecnológicos desembocaram no projeto SIM - açôes integradas de consentimento para ocupação e resistência, cujo enfoque é a experiência de autonomia testada pela manipulação de sonoridades, visualidades, contatos e deslocamentos corporais como fatores restritivos, coercivos e sugestivos de açóes cujo caráter não planejado provoca desestabilização ou consolidaçãoo de padróes de resposta (Britto, 2011, p. 6-7).

Pesquisadoras como Fabiana Dultra Britto e Maíra Spanghero, entre outros, vêm abordando a tessitura dos processos artísticos do Cena 11 como uma continuidade composta por trajetos multidirecionais, em que a relaçáo corpo e ambiente parece prevalecer como ponto reincidente nas preocupaçôes de Ahmed. Britto colaborou como interlocutora teórica do grupo e Spanghero escreveu o livro $A$ dança dos encéfalos acesos (2003), cuja incursão teórica sobre dança e tecnologia fez uso de cinco criaçóes do grupo para concluir que "[...] a dança dos encéfalos acesos mostra que a tecnologia mais refinada é aquela que mora no corpo" (Spanghero, 2003, p. 122).

Nesse sentido, ao cunhar a fricção entre percepçáo e adaptação como disparadora da composiçáo generativa presente em $Z$, subentende-se que perceber e adaptar são verbos decorrentes de um corpo implicado ativamente nas relaçóes que trava com seu entorno.

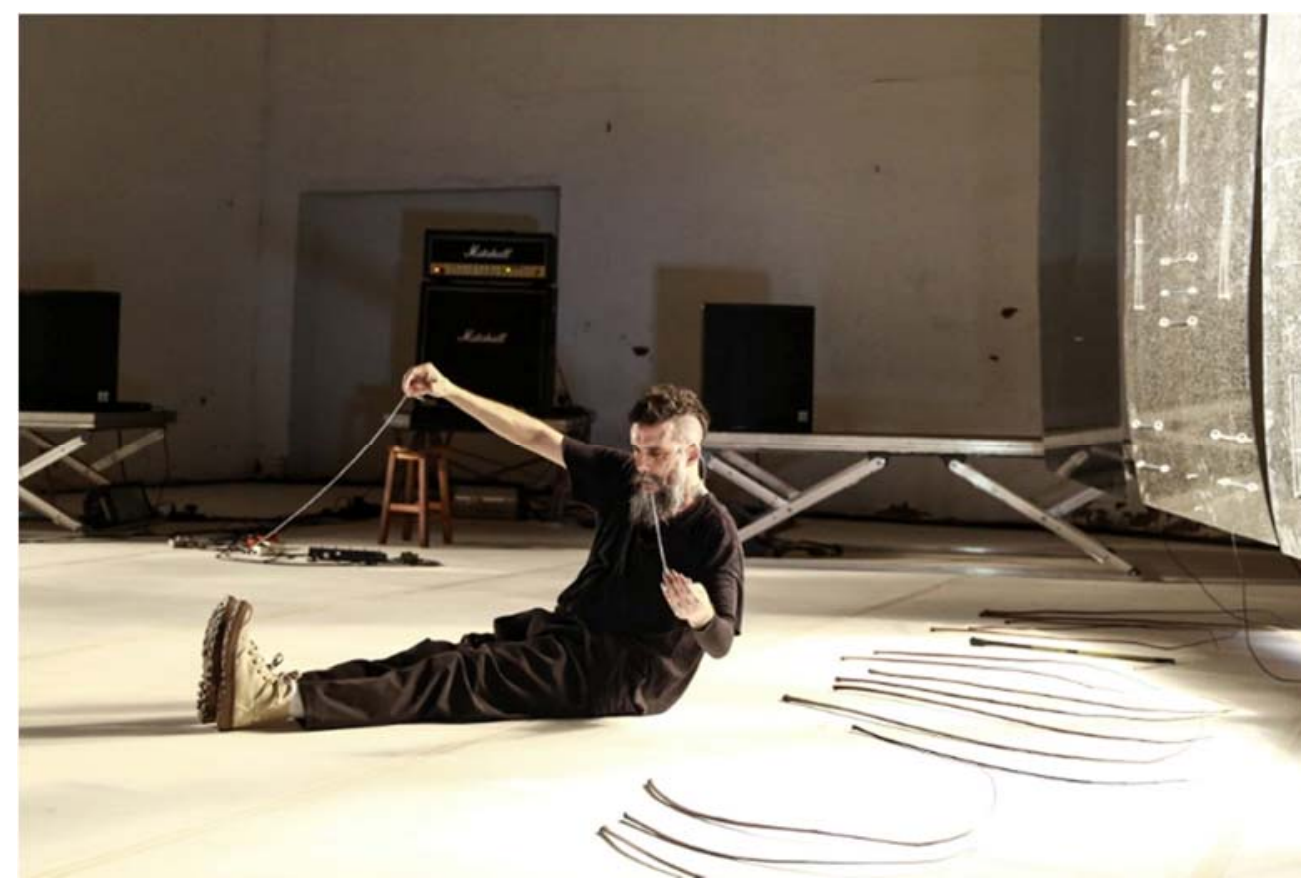

Figura 6 - Alejandro Ahmed em Z. Fonte: Foto de Beto Assem. 
No âmbito dos estudos cognitivos, a percepção vem sendo concebida não mais como um processo cerebral de representação interna, mas sim como uma atividade enativa, deflagrada pelo movimento e pela interação com o ambiente. Para o filósofo da mente, Alva Noë (2004), a percepção é algo que nos acontece, de modo que o conteúdo perceptual náo é uma fotografia representada internamente, mas sim uma exploração ativa e corpórea. Para perceber, é preciso seguir a pista dos movimentos relativos ao mundo, de acordo com um conhecimento corpóreo prático (Nöe, 2004). "Do ponto de vista da ênfase enativa, toda representação perceptual, resultante da atividade, tanto dorsal como ventral, depende da ação das habilidades sensóriomotoras do perceptor" (Nöe, 2004, p. 19, tradução nossa) ${ }^{9}$.

A noção de composiçâo generativa, utilizada em $\mathrm{Z}$, parece resvalar na ideia de arte generativa criada por sistemas autônomos em combinaçóes matemáticas ou aleatórias, já que as frequências produzidas pela vibração das cordas da guitarra geram microfonia, tremores e queda de materiais, dando a ver a comunicação entre todas as materialidades postas ali. Por outro lado, tal composiçáo generativa também parece sublinhar a concepçáo de coreografia como uma tecnologia de dança, medrada por um corpo que transita entre aquilo que já conhece e as imprevisibilidades do ambiente.

Há de se dizer que o artista sofre de osteogênese imperfeita, possui grande fragilidade óssea e teve perda considerável da audição nos últimos anos. Assim, mover passa a ser uma construçáo de possibilidades permeada por riscos, enquanto que os sons, em detrimento de formularem ordenaçóes melódicas e harmônicas, convertem-se em trocas entre materialidades autônomas.

\section{Percepçáo e Cognição: níveis de interaçáo entre movimento e som}

No campo de estudos sobre a escuta humana, a ciência esteve, majoritariamente, ocupada em investigar o som como objeto concreto e exterior ao corpo. No entanto, ao averiguar somente o som como fenômeno externo, a percepção tornou-se secundária.

$\mathrm{Na}$ perspectiva da cognição corporificada, o som passa a ser balizado pela experiência de escutar, deflagrando que a relaçáo entre o corpo e as sonoridades do mundo é mediada pela percepçáo. 
Marc Leman (2008), um dos mais importantes autores da área da Cogniçáo Musical Incorporada (Embodied Music Congnition) $)^{10}$, defende que a percepção musical é acionada pelo sistema sensório-motor (Leman, 2008). Em seu livro, Embodied Music Cognition and Mediation Technology, Leman introduz um modelo que descreve a relaçáo entre comportamento humano e ambiente, analisando a sincronia entre ação e percepçáo, e explorando diferentes níveis de acoplamento do corpo com a música. Apoiado sobre a hipótese da intencionalidade corporal - tributária da ideia de percepção como açâo simulada (Berthoz, 1997) -, o autor argumenta que o corpo humano é um mediador biologicamente desenhado que transfere energia física para um nível mental - ativando experiências, valores e intençóes - e, em um processo inverso, transfere representaçóes mentais para a forma material.

Alain Berthoz (1997), engenheiro e neurofisiologista francês, ao afirmar que a percepção é uma ação simulada, ponderou que esta não poderia anteceder a cogniçấo. Para ele, perceber é conhecer, pois percepção não é somente interpretação de mensagens sensoriais, mas é julgamento e tomada de decisão. A partir de estudos oriundos do pragmatismo e da psicologia funcional do século XIX, Berthoz defendeu a percepção como uma forma de predição, acionamento e ignição, em detrimento de sua acepção como registro ou armazenamento. No livro Le sens du moviment, argumentou que as funçóes cognitivas são dotadas de um impulso em direção ao desenvolvimento da capacidade de reorganizar a ação em função dos acasos, processo que exigiria o desenvolvimento de uma memória do passado, das faculdades de predizer e da simulação do futuro (Berthoz, 1997).

Com base nas pesquisas de Berthoz, Marc Leman explica que a intencionalidade corporal pode ser compreendida como uma emergência da relação entre ação e percepção, ativada pelo sistema sensório-motor, que atuaria como um disparador desse processo, ou seja, seria o efeito emergente do acoplamento percepção-açãoo (Leman, 2008).

No âmbito da experiência sonora, a intencionalidade corporal articularia formas sonoras como ressonâncias no comportamento do corpo humano, já a intencionalidade cerebral interpretaria a fonte das intençôes atribuídas à música. Assim, o sistema sensório-motor seria responsável por transformar as energias musicais num mundo imaginário formado por objetos contendo qualidades, intençóes, objetivos e valências (isto é, atributos físi- 
cos que são treináveis, como resistência, velocidade, coordenação, flexibilidade, mobilidade etc.) e vice-versa (Leman, 2008).

Tal perspectiva entende que a informaçáo sensorial (energia musical do ambiente) evoca traços motores (simulados ou executados), como se a música fosse produto de sua própria ação no corpo (Leman, 2008). Os gestos utilizados por um instrumentista ou por um corpo não especialista que se move ao som de uma música podem ser vinculados às explosóes de energia musical que ressoam fora do corpo, gerando correlaçóes sonoras e, sobretudo, rítmicas (Leman, 2008).

Para Leman, há três níveis de imitação corporal relacionados ao som. O primeiro é a sincronização, regida pelo princípio ideomotor, em que padróes rítmicos evocam ressonâncias biomecânicas num nível sensório-motor mais baixo. Bater com os pés no chão, acompanhando o ritmo de uma fonte sonora externa, ou mover o corpo seguindo a pulsação de uma música são alguns exemplos básicos desse tipo de interaçáo. O segundo nível é a sintonização, norteada por um endereçamento de alto nível, expresso em termos de melodia e harmonia. Semelhante à ideia de sintonização de rádio, em que um radiorreceptor se ajusta ao comprimento de onda do radioemissor, a sintonia se dá náo pelo ritmo, mas pela apreensão das frequências. Quando utilizamos um diapasão para cantar, por exemplo, sintonizamos a nota emitida por sua vibração metálica à nossa vibração vocal. Por último, há a empatia, que corresponderia à imitação da intencionalidade emocional da música, ou seja, sua expressividade (Leman, 2008).

Se aplicássemos tais níveis de comunicação entre corpo e som às obras supracitadas - Peças Fáceis e $Z$-, teríamos de levar em conta as lógicas de composição estabelecidas em cada processo de criação. Peças Fáceis, embora apresente sons e movimentos não previstos em alguns momentos, congrega gramáticas musicais e coreográficas pré-definidas. Já $Z$ é propositalmente criado a partir de acontecimentos sonoros e corpóreos inacabados, entre fisicalidades distintas: corpo, guitarra, chão, placas magnéticas, correntes e outros.

Em Peças Fáceis, sincronia, sintonização e empatia regulam-se ora pelo jogo entre os minuetos barrocos e outras referências musicais entoadas vocalmente, ora por meio do som de instrumentos musicais, fazendo movimento e som coexistirem num regime de mutualidade organizada, que cul- 
minam em campos harmônicos conhecidos. O espetáculo se inicia com um jogo de respiraçóes que, aos poucos, é substituído por notas de referência entoadas por vibraçóes, vocalises e cantos difônicos ${ }^{11}$. Entre movimentos combinados e repetiçóes gestuais, as performers executam um Minueto em Sol Maior de Christian Petzold e Johan Sebastian Bach, emitindo duas vozes em contraponto. Num segundo momento, sons percutidos num violáo acionam os movimentos de um corpo em deslocamento no chão. Integrando sincronização e sintonização, ruídos gradualmente assumem a forma tonal de mais um minueto de Petzold e Bach - agora tocado no violáo em concomitância com movimentos de pernas, quadril e braços, no chão. Em outros trechos da obra, repertórios culturais se friccionam, anunciando um encontro de empatia corpo-sonora, desencadeado pelas intencionalidades memoriais entre som e movimento. Isso aparece quando a performer Janice Vieira dança e cantarola fragmentos soltos e desconexos da canção $O$ bêbado equilibrista (de Joáo Bosco e Aldir Blanc), ou quando toca castanholas com restos de movimentos que lembram uma dança flamenca ${ }^{12}$.

Já na obra $Z$, os níveis comunicacionais entre corpo e som se revelam em outras dimensôes: movimentos e batidas rítmicas ora são sincrônicos, ora são aleatórios; a sintonização gera encontros e desencontros randômicos entre frequências diferentes e a empatia opera em termos de estranhamento entre o que soa e o que se move. Quando o performer Alejandro Ahmed, sentado numa cadeira, com uma guitarra elétrica apoiada verticalmente no colo, toca as cordas de aço com dedeiras/palhetas de aço nos dedos das máos, seus gestos sáo ampliados no ar, criando desenhos sincrônicos e anacrônicos aos sons produzidos pela guitarra. $\mathrm{O}$ overlapping sonoro das notas das cordas - por meio do uso do aparelho de looping que grava um som sobre outro - encontra os gestos das máos e da cabeça do performer, traçando - mais do que uma sintonização harmônica - um outro tipo de sobreposição entre som e movimento. Quanto à empatia, é interessante notar que o jogo de frequências desarmônicas, decorrentes do tipo de sonoridade produzida pelo uso náo convencional da guitarra ou da voz, podem provocar no público um desconforto de escuta. Depreende-se que a relaçáa entre movimento e ruído, entâo, suscita, empaticamente, um estado de desestabilização, não só no corpo-performer, mas também no corpo-espectador.

Ainda que classifique interaçôes múltiplas em apenas três possibilidades, essa tríade formada por sincronizaçâo, sintonizaçâa e empatia pode nos 
ajudar a compreender respostas imediatas entre escuta, movimento e produçáo sonora no corpo. No entanto, se tentássemos investigar internamente as elaboraçóes coreográficas travadas por um corpo especialista em dança, quando a proposta é produzir som e movimento em diferentes padróes organizacionais, que outros mapeamentos cognitivos poderiam emergir?

O médico, biólogo e físico-químico estadunidense Gerald Edelman, em Wilder than the sky (2005), apresenta o sistema nervoso como uma variedade de pequenas partes segregadas em suas funcionalidades, que se interagem em diversas combinaçóes capazes de gerar propriedades integradas. Seu objetivo é mostrar como um sistema complexo pode detonar a integraçáo de suas partes e, ao mesmo tempo, manter muitos estados diferenciados cruzando as propriedades dessas partes (Edelman, 2005).

Certamente, comportamentos complexos como dançar, cantar ou tocar um instrumento envolvem aspectos cognitivos de alto nível, como planejar ou imaginar movimentos e sons. Entretanto, pesquisas recentes no campo da Neurocogniçáo da Dança têm atestado a importância das decisôes locais (não centralizadas pelo Sistema Nervoso Central) em processos sensório-motores como caminhar ou mover um braço, em conjunto com operaçôes cognitivas mais complexas.

Com base na observação e análise neurofisiológica do movimento de insetos e do conhecimento biológico, Cruse \& Schilling defendem a hipótese de que o sistema cognitivo não forma um sistema independente, separado da ação reativa das partes periféricas do corpo, mas sim atua em constante transição entre o controle reativo (sensório-motor) e as soluçóes mais centralizadas (Cruse; Schilling, 2016, p. 53-61): “Tanto o controle motor quanto o pensamento (e a imaginação) parecem ser produzidos pelos mesmos mecanismos neuronais, uma descoberta de grande impacto para o entendimento de nossos cérebros" (Cruse; Schilling, 2016, p. 54, tradução nossa).

Esse controle motor reativo diz respeito ao sistema sensóriodirecionado, cuja função é coordenar os movimentos de diferentes partes do corpo e reagir a perturbaçóes inesperadas sem o comando dos centros mais altos (higher centres). Ou seja, trata-se de compreender que o sistema sensório-motor pode decidir e agir, localmente, entre posiçôes, equilíbrios e flu- 
xos, de acordo com seu repertório de motricidade e suas habilidades de ação (Cruse; Schilling, 2016).

Isso significa dizer que tarefas complexas, como mover o corpo de acordo com um hábito específico de movimento que requer treinamento, em concomitância com a ação de cantar dentro de uma cadeia melódica específica, deflagra não só um jogo entre sincronia, sintonização e empatia, mas também operaçóes integradas entre o sistema sensório-motor e o sistema nervoso central. Seria o mesmo que travar uma conversa íntima entre percepção e cognição, entendendo que a percepção de cada corpo se diferencia por seus repertórios motores e habilidades de açáo. (Fogassi; Ferrari; Gesierich; Rozzi; Chersi; Rizzolatti, 2005 apud Cruse; Schilling, 2016).

Em Peças Fáceis, a ideia de habilidade aparece sob o contorno de uma dança cujos movimentos são reconhecíveis dentro de um recorte estético e de sons que migram do ruído e do silêncio para organizaçôes tonais. Assim, subentende-se que as artistas performam seus repertórios corporais e musicais, integrando-os.

O performer de $Z$, na contramão da feitura de gestos reconhecíveis e da funcionalidade do instrumento musical, parece buscar a exposiçáo das negociaçôes neuromotoras entre as distintas camadas do jogo percepçáocognição.

Todavia, é mister ressaltar que não há possibilidade de anular os hábitos motores presentes em qualquer interaçáo som-movimento, mesmo que seja objetivo de uma pesquisa artística demonstrar encontros inesperados entre o que soa e o que se move. Ora, se a intencionalidade corporal articula formas sonoras como ressonâncias no sistema sensório-motor, e esse é sempre dotado de um repertório, a comunicação entre movimento e som não é um acontecimento desconhecido, mas uma recorrência cinética.

Nesse sentido, quando Ahmed responde ao som como matéria bruta, traçando movimentos que lhes são conhecidos - porque conquistados pelo hábito de sua motricidade -, o que vemos não é um encontro aleatório, mas o exercício de expor a comunicação da energia sonora se dissipando no espaço com a energia cinética produzida por um corpo especialista em determinada forma de mover. 


\section{Cognição e Cultura: sistemas em ressonância}

A indissociabilidade entre percepção e ação, aventada aqui como principal agente na comunicação entre som e movimento, é tributária das dinâmicas presentes no jogo entre natureza e cultura. Para Marc Leman, o modo como um organismo recebe as energias sonoras do ambiente e as transforma em açóes ou conceitos abstratos depende de uma perspectiva ecológica, mediada pela ressonância entre os domínios do natural e do cultural (Leman, 2008).

Tomando como exemplo a construção de instrumentos musicais, Leman apresenta o ciclo tocar-ouvir-julgar-mudar como um processo de modelação de equilíbrio entre as limitaçôes da natureza e da cultura no âmbito do reconhecimento sonoro. Para fabricar um sino, na cultura ocidental, foi necessário tornear a qualidade desarmônica do bronze, até que sua materialidade se adequasse a um ideal harmônico. Tocar o objeto para gerar vibrações físicas; ouvir para apreender as vibraçóes; julgar para comparar e mudar as condiçôes físicas do objeto com vistas à adequação cultural para futuro julgamento, essas seriam as premissas de um ciclo de açáo e reação guiado por um ideal harmônico culturalmente localizado (Leman, 2008).

Esse exemplo - calcado na construçáo de um artefato - aponta para uma discussão ampla sobre a qualidade natural-cultural da percepção de sons harmônicos e desarmônicos ${ }^{13} \mathrm{e}$ da relação cognitiva que temos com o que ouvimos. Apesar de ponderar diferentes visóes sobre o quanto natureza e cultura poderiam determinar as categorias da escuta, o autor defende que essas duas instâncias atuam numa via de máo dupla, por meio de um processo de ressonância medrado pela percepçáo-ação do sujeito (Leman, 2008).

Em Peças Fáceis, as artistas vocalizam em contraponto, a partir de minuetos de Bach e Petzold, enquanto se movem com repetição de gestos traçados em diagonais e círculos, gerando combinaçóes de sons harmônicos e movimentos ordenados. Em outro momento, os minuetos são atravessados por outras referências sonoras, como sons percutidos e aleatórios, cançôes sefarditas, rasgueos espanhóis, valsa, baiáo e coco. Do que parece ser uma miscelânea sonora, a ordem sempre se coloca em relevo, organizando a polifonia em linhas melódicas autônomas que se cruzam harmonicamente. Numa busca precisa pela afinação e pela tonalidade, Peças Fáceis revela a ex- 
ploração das referências musicais das performers, conflitando os repertórios gestuais a um constante entrainment ${ }^{14}$ sonorocoreográfico.

$Z$, por sua vez, explora outros acordos entre natureza e cultura, porquanto expóe a ambiguidade da percepção daquilo que não é harmônico e estável.

A relação entre percepção sonora e ambiguidade pode ser justificada pelo caráter evolutivo que demarcou a preferência pelos tons estáveis. Antes da produção humana de artefatos, muitos sons desarmônicos caracterizavam a relaçáo entre corpo e ambiente, ao passo que, após o uso reincidente de materiais manufaturados, a percepçáo foi se adequando a um ambiente de tons harmônicos. E não bastasse a preferência pelos tons harmônicos, estudos atestam que há ainda a preferência perceptual pela frequência fundamental do som (pitch), em detrimento dos sobretons (Leman, 2008):

Durante o curso da evolução, estabilidade e recompensa, e consequentes funçôes biológicas podem se desenvolver em direção ao aspecto da informação que é mais estável (menos ambíguo) na estrutura da energia física. Em contraste ao pitch, por exemplo, a estrutura de fases do tom harmônico complexo é não estável. Consequentemente, sua percepção será altamente ambígua (Leman, 2008, p. 60-61, tradução nossa).

Tais ajustes evolutivos são tributários de uma densa relação entre cognição e cultura, cuja dinâmica evolutiva trava negociações constantes entre corpo e ambiente. O que é mais ou menos estável - em termos de harmonia ou desarmonia no caso do som e de padronização gestual no que tange ao movimento - comporta não só as escolhas estéticas empreendidas na produção de uma obra, como também os contextos culturais e de investigação que a cercam.

Assim, não se trata de compreender a evolução cultural das interaçóes entre corpo e som como uma progressão linearmente direcionada: "Em vez disso, esta [a evolução cultural] pode ser entendida como um efeito da interação entre restriçóes culturais locais e restrições naturais, o que pode levar à formação de trajetórias em direção a atratores culturais particulares" (Leman, 2008, p. 70-71, tradução nossa).

\section{Consideraçóes Finais}

Este estudo aventou alguns aspectos possíveis da trama entre som e movimento em processos artísticos cujo interesse ronda a relação entre dan- 
ça e produção sonora. Com a intenção de avançar nos debates sobre corpo, cognição, arte e cultura, incursionamos pelas pesquisas de alguns autores das Neurociências e das Ciências Cognitivas, utilizando inferencialmente ${ }^{15}$ suas acepções.

Os processos artísticos aqui abordados, ao colocarem o corpo como objeto central de sua criação - por meio de uma postura investigativa resultante de poéticas desenvolvidas ao longo dos anos -, nos convidam a olhar para além da análise crítica e estética de suas obras. São artistas inventando corporalidades e sonoridades complexas, cujas implicaçóes suscitam outras formas de pensar a relaçáo entre corpo e ambiente. Ademais, essa interface de investigação, ao abordar experiências artísticas híbridas, corrobora para ampliar a própria noção de dança. Ora, a dança, como campo intermitente de construçáo, traz em seu bojo uma vocação interdisciplinar - por vezes indisciplinar ${ }^{16}$ - para dar conta de toda diversidade que produz. Por conseguinte, os problemas oriundos dessa arte expandida levam-nos a argumentar também com ferramentas teóricas advindas de várias searas do conhecimento.

É certo que o debate aqui interposto sobre as interações entre dança e música em criaçóes artísticas híbridas está longe de ser esgotado. Todavia, com algumas pistas lançadas, podemos concluir que movimento e som, codependentes em sua processualidade perceptual-cognitiva-cultural, insuflam não só uma trama biocultural recíproca, mas deflagram também a possibilidade de invençôes artísticas cada vez mais atentas à natureza processual e provisória do corpo.

\section{Notas}

1 Inúmeros trabalhos contemporâneos apresentam artistas com formações mistas, atuando em obras híbridas que cruzam dança, música e teatro: (Not) a Love Song (2007), do coreógrafo francês Alain Buffard, En attendant (2010) e Cesena (2011), da coreógrafa belga Anne Teresa De Keersmaeker, Can we talk about this? (2011), do diretor e coreógrafo inglês Lloid Nilson, Avante, Marche! (2015), dos diretores belgas Alain Platel e Frank Van Laecke, Cabras (2016), da encenadora brasileira Maria Thaís, Outros (2018), do encenador Márcio Abreu para o grupo mineiro Galpão e Arco (2018), do bailarino e músico brasileiro Ângelo Madureira, entre outros. 
2 Imagens do processo podem ser vistas no minidocumentário da montagem. Disponível em: <https:/www.youtube.com/watch?v=pG0cDfyZQRU>, bem como no site do projeto Plataforma Sonorocoreográfica: $<$ https://www.pecasfaceis.wixsite.com/proposicao>.

3 Vocalise é um exercício vocal utilizado por estudantes e cantores, que consiste em cantar uma ou mais vogais em linhas melódicas especificamente arranjadas (Anglés; Pena, 1954).

$4 \mathrm{O}$ contraponto remonta à música polifônica do século XVI e demarca a utilização de uma ou mais linhas melódicas autônomas ocorrendo ao mesmo tempo, mas conectadas por uma lógica intervalar e harmônica. "O contraponto é a simultaneidade de melodias, com cada linha seguindo independentemente das demais horizontalmente, e alinhando-se para fazer sentido harmônico verticalmente [...]" (Martineau, 2014, p. 281).

5 O Grupo Pró-Posição foi fundado em 1973, em Sorocaba/SP, pelos bailarinos Janice Vieira e Denilto Gomes (1953-1994). Com produçóes ousadas, engajadas e ligadas à contracultura, o grupo se destacou no panorama da dança brasileira das décadas de 1970 e 1980. Durante dez anos, participou ativamente de movimentos como Teatro de Dança na Sala Galpão, em São Paulo, e Oficina Nacional de Dança Contemporânea, da Bahia, integrando uma primeira geração de artistas da dança contemporânea no Brasil. Em 2007, o grupo foi retomado por meio da parceria entre Janice Vieira e Andréia Nhur, com obras autobiográficas, centradas na relação entre corpo, memória e linguagens híbridas (dança, teatro e música). Desde então, atua ininterruptamente, produzindo espetáculos, pesquisas e atividades formativas. Entre suas obras mais importantes, destacam-se: Boiação (Prêmio APCA, 1976), Silêncio dos Pássaros (Prêmio APCA, 1978), A trilogia do cisne (composta por Swan Corpo Adaptado; O Cisne, minha mãe e eu e Linhagens - Prêmio APCA 2013 pela Pesquisa em Dança), Vis-à-Vis (Prêmio Governador do Estado, 2013) e Peças Fáceis (Prêmio Denilto Gomes 2017, indicado ao APCA 2017 de melhor espetáculo de dança). Em 2013, a história do grupo foi registrada no documentário Figuras da Dança-Janice Vieira (produzido pela Sáo Paulo Cia. De Dança), em cartaz nos canais TV Cultura, CURTA e ARTE 1. Disponível em: $<$ https://www.proposicaodanca.com.br>.

6 O termo coreografia, forjado inicialmente em 1700, com a publicação do livro Choreographie ou l'Art de Décrire la Danse par Caractères et Signes Démonstratifs, de Raoul-Auger Feuillet (1700), cunhava um isomorfismo entre a sala de dança e uma página em branco, ou seja, imputava uma perspectiva de escrita linear 
ao ato de criar uma dança (Lepecki, 2010). Essa visão, acrescida ao senso comum que define coreografia como junção sequencial de passos, foi impactada por usos diversos do espaço-tempo nas danças modernas e contemporâneas, a ponto de realocar o debate para outras perspectivas acerca do termo.

7 A Companhia surgiu na cidade de Florianópolis/SC em 1993 e, desde então, atua na produção artística de dança tendo se tornado referência nacional e internacional pela relevância artística de suas propostas e pelo caráter investigativo ininterrupto. Sua trajetória de pesquisa recebeu do Ministério da Cultura e Governo Federal a Ordem do Mérito Cultural 2014. Foi premiada pela Associação Paulista de críticos de dança (APCA) por quatro vezes - 2014, 2012, 2007, 1997 - e também pelo Prêmio Bravo, Prêmio Sérgio Motta de Arte e Tecnologia, Transmídia Itaú Cultural, Bolsa Vitae e Rumos Itaú Cultural. As produçóes da companhia são: Respostas sobre Dor (1994); O Novo Cangaço (1996); In'Perfeito (1997) - Prêmio APCA por Melhor Concepção Cênica; $A$ Carne dos Vencidos no Verbo dos Anjos (1998); Violência (2000); Projeto SKR (2002); SKINNERBOX (2005); Pequenas frestas de ficção sobre realidade insistente (2007) - Prêmio Sergio Motta de Arte e Tecnologia / Prêmio Bravo! Prime de Cultura, Melhor Espetáculo de Dança / Prêmio APCA de Pesquisa em Dança; Embodied Voodoo Game (2009); Guia de ideias correlatas (2009); SIM\&̊lt; Açôes integradas de consentimento para ocupação e resistência (2010); Carta de amor ao inimigo (2012) - Prêmio APCA por Trajetória de Pesquisa em Dança; Sobre expectativas e promessas (2013); Monotonia de Aproximação e Fuga para 7 Corpos (2014) - Prêmio APCA por Melhor Criação em Dança e Protocolo Elefante <https://www.cena11.com.br>.

8 Trechos do espetáculo podem ser vistos em: <https://vimeo.com/281288085>.

9 Para Noë, perceber é uma destreza da atividade corporal resultante da indissociabilidade entre as funções cerebrais. Ao discutir percepção visual, o autor contraria a separação proposta por Bridgeman (1992; 2000 apud Noë, 2004), em que a área ventral do cérebro seria responsável pela representação perceptual e identificação, enquanto que a área dorsal estaria ligada à ação. Antes, a perspectiva enativa emprega uma abordagem integrada entre perceber e agir, tendo o movimento como agente catalisador (Noë, 2004).

10 A Cognição Musical Incorporada (Embodied Music Cognition) é uma área da musicologia interessada no papel desempenhado pelo corpo humano em interação com atividades musicais. O paradigma da Cognição Musical Incorporada é uma extensão de um paradigma anterior, em que cognição e percepção são entendidas como eventos acoplados. Atualmente, dois grandes campos dividem 
os interesses dos estudos nessa seara: 1 - a exploraçáo da noção de incorporaçáo (embodiment) e seus desdobramentos no tocante à relaçáo entre corpo, gestualidade expressiva e música e 2 - a pesquisa da cogniçáo incorporada ligada aos afetos musicais (Leman et al., 2018).

11 O canto difônico é uma técnica vocal que permite ao cantor produzir mais de uma nota ao mesmo tempo, através da emissão da frequência fundamental e, concomitantemente, de um de seus harmônicos.

12 Teaser do espetáculo: <https://www.youtube.com/watch?v=UN5fqEigrIk>.

13 Os sons harmônicos são estáveis, porque edificados sobre a relação entre uma frequência fundamental e seus múltiplos inteiros, enquanto os sons desarmônicos são instáveis pois são compostos de tons parciais que não são múltiplos inteiros da frequência fundamental (Leman, 2008). Alguns instrumentos de percussão como pratos e carrilhóes, por exemplo, criam sons complexos e desarmônicos, ao passo que, em instrumentos de corda como violáo ou piano, os sons são estáveis (já que se aproximam de ou equivalem a múltiplos inteiros da frequência fundamental).

$14 \mathrm{O}$ conceito de entrainment tem sido aplicado à música com o intuito de compreender as diferentes interações entre os sistemas rítmicos e suas relações com a atenção humana. Os estudos de Martin Clayton (2007) sobre a interação rítmica em experiências musicais irregulares indicaram a possibilidade de emergência de uma métrica natural no corpo. Mas tal processo envolve não só a relaçáo sincrônica entre os participantes de uma performance musical, mas o contínuo ajuste mútuo que a constitui, bem como o retardar e o adiantar o tempo como experiência viva de tocar/cantar junto (Dahl et al., 2010).

15 A ideia de inferência aparece aqui como recurso utilizado para transpor noçóes estudadas em campos como Neurociências, Ciências Cognitivas e Musicologia para o âmbito dos processos artísticos em dança. Assim, sem a intenção de aplicar conceitos oriundos de experimentos laboratoriais a uma reflexão acerca do fazer artístico, fizemos uma apropriação inferencial de algumas ideias como tentativa de balizar essa reflexáo.

16 O conceito de indisciplinaridade aparece nos escritos de Helena Katz e Christine Greiner no âmbito dos estudos do corpo e da dança. O termo extrapola a limitaçáo das molduras disciplinares, sugerindo que os prefixos inter e trans não seriam suficientes para abarcar o fluxo de saberes que atravessam determinados campos de conhecimento (Greiner, 2005). 


\section{Referências}

ANGLÉS, Higinio; PENA, Joaquín. Diccionario de la Música Labor. Tomo II. Barcelona: Editorial Labor, 1954.

BERTHOZ, Alain. Le Sens du Mouvement. Paris: Editions Odile Jacob, 1997. BRITTO, Fabiana Dultra. Corpo, dança e ambiente: configurações recíprocas. In: ENCONTRO NACIONAL DE PESQUISADORES EM DANCA, 2., 2011. Anais... Salvador: Associação Nacional de Pesquisadores em Dança, 2011. P. 1-10. Disponível em: <http://www.portalanda.org.br/anaisarquivos/6-20112.pdf>. Acesso em: 15 jan. 2020.

CRUSE, Holk; SCHILLING, Malte. Getting cognitive. In: BLÄSING, Bettina; PUTTKE, Martin; SCHACK, Thomas (Ed.). The neurocognition of Dance: mind, movement and motor Skills. New York: Psychology Press, 2016. P. 53-74.

DAHL, Sofia et al. Gestures in Performance. In: GODOY, Rolf; LEMAN, Marc. Musical Gestures: sound, movement and meaning. New York: Routledge, 2010. P. 36-68.

EDELMAN, Gerald. Wider than the sky: a revolutionary view of consciousness. London: Penguin, 2005.

FEUILLET, Raoul-Auger. Choreographie, ou l'art de d'écrire la danse par caractères, figures et signes 10 démonstratifs. Paris: Bibliothèque Nationale de France, 1700. Disponível em: <https://gallica.bnfffr/ark:/12148/btv1b86 232407/f15.image>. Acesso em: 18 jan. 2020.

FILHO, Rui._Z. Resenhas do JUNT4: festival internacional de dança. Antropositivo, São Paulo, 2018. Disponível em: <https://www.antropositivo.com.br /single-post/2018/11/15/JUNT4-2018>. Acesso em: 18 jan. 2020.

FROST, Samantha. Biocultural creatures: toward a new theory of the human. North Carolina: Duke University Press, 2016.

GREINER, Christine. O Corpo: pista para estudos indisciplinares. São Paulo: Annablume, 2005.

KATZ, Helena. Peças Fáceis verticaliza os estudos sobre memória e gesto. O Estado de Sáo Paulo, São Paulo, ano 138, 2017. P. 36. Disponível em: $<$ https://cultura.estadao.com.br/noticias/teatro-e-danca,pecas-faceis-verticaliza-osestudos-sobre-memoria-e-gesto,70001803371 >. Acesso em: 02 jan. 2020.

LEHMANN, Hans-Thies. Teatro pós-dramático. Tradução de Pedro Süssekind. São Paulo: Cosac \& Naify, 2007. 
LEMAN, Marc. Embodied Music Cognition and Mediation Technology. Cambridge: The MIT Press, 2008.

LEMAN, Marc et al. What Is Embodied Music Cognition? In: BADER, Rolf (Ed.). Springer Handbook of Systematic Musicology. Berlin; Heidelberg: Springer Handbooks, 2018. P. 747-760.

LEPECKI, André. Planos de Composição. In: GREINER, Christine; SANTO, Cristina Espírito; SOBRAL, Sonia. CARTOGRAFIA Rumos Itaú Cultural Dança 2009-2010. São Paulo: Itaú Cultural, 2010. P. 13-20.

LOUPPE, Laurence. Corpos híbridos. In: SOTER, Silvia; PEREIRA, Roberto (Org.). Liçóes de Dança 2. Rio de Janeiro: UniverCidade Editora, 2000. P. 2740.

MARTINEAU, John (Org.). Quadrivium: as quatro artes liberais da aritmética, da geometria, da música e da cosmologia. Tradução de Jussara Trindade de Almeida. São Paulo: É Realizaçóes, 2014.

NHUR, Andréia. Memórias de mãe e filha. Revista Aspas, São Paulo, Universidade de São Paulo, v. 9, n. 1, p. 185-197, ago. 2019. Disponível em: <https://doi.org/10.11606/issn.2238-3999.v9i1p185-197>. Acesso em: 15 jan. 2020.

NOË, Alva. Action in perception. Cambridge: MIT Press, 2004.

SERAFIN, Karin. Z. Florianópolis: 2018. Disponível em: <https://karinserafin. wixsite.com/artistas/z>. Acesso em: 18 jan. 2020.

SPANGHERO, Maíra. A dança dos encéfalos acesos. São Paulo: Itaú Cultural, 2003.

WISNIK, José Miguel. O Som e o sentido: uma outra história das músicas. São Paulo: Companhia das Letras, 2006.

Andréia Nhur é artista, pesquisadora e professora do Departamento de Artes Cênicas da Escola de Comunicaçôes e Artes da Universidade de São Paulo.

ORCID: http://orcid.org/0000-0002-0157-0334

E-mail: andreianhur@usp.br

Este texto inédito também se encontra publicado em inglês neste número do periódico.

Recebido em 30 de janeiro de 2020 Aceito em 12 de maio de 2020 
Este é um artigo de acesso aberto distribuído sob os termos de uma Licença Creative Commons Atribuiçáo 4.0 Internacional. Disponível em: <http://creative commons.org/licenses/by/4.0>. 